\title{
Powder X-ray diffraction of trimethoprim Form I, $\mathrm{C}_{14} \mathrm{H}_{18} \mathrm{~N}_{4} \mathrm{O}_{3}$
}

\author{
Jerry Hong, ${ }^{1}$ Joseph T. Golab, ${ }^{1}$ James A. Kaduk $\mathbb{Q}^{2,3, a)}$ Amy M. Gindhart, ${ }^{4}$ and Thomas N. Blanton $\mathbb{}^{4}$ \\ ${ }^{1}$ Illinois Mathematics and Science Academy, 1500 Sullivan Rd., Aurora, Illinois 60506-1000, USA \\ ${ }^{2}$ Illinois Institute of Technology, 3101 S. Dearborn St., Chicago, Illinois 60616, USA \\ ${ }^{3}$ North Central College, 131 S. Loomis St., Naperville, Illinois 60540, USA \\ ${ }^{4}$ ICDD, 12 Campus Blvd., Newtown Square, Pennsylvania 19073-3273, USA
}

(Received 2 December 2019; accepted 10 December 2019)

\begin{abstract}
Trimethoprim crystallizes in the triclinic space group $P-1$ (\#2) with $a=10.5085(3), b=10.5417(2)$, $c=8.05869(13) \AA, \alpha=101.23371(21), \beta=112.1787(3), \gamma=112.6321(4)^{\circ}, V=743.729 \AA 3$, and $Z=2$. A reduced cell search in the Cambridge Structural Database yielded three previous structure determinations, using data collected at $100 \mathrm{~K}, 173 \mathrm{~K}$, and room temperature. In this work, the sample was ordered from the United States Pharmacopeial Convention (USP) and analyzed as-received. The room temperature $(295 \mathrm{~K})$ crystal structure was refined using synchrotron $(\lambda=0.412826 \AA)$ powder diffraction data and optimized using density functional theory techniques. We found similar hydrogen bonding patterns with the previous determinations. In addition, we identified two $\mathrm{C}-\mathrm{H} \cdots \mathrm{O}$ hydrogen bonds, which also contribute to the crystal energy. When comparing the previously reported trimethoprim structure determinations, the unit cell length lattice parameters were found to contract at lower temperatures, particularly $100 \mathrm{~K}$. All structures show reasonable agreement, with unit cell length differences ranging between 0.05 and $0.15 \AA$. The diffraction data for this study were collected on beamline 11-BM at the Advanced Photon Source, and the powder X-ray diffraction pattern of the compound has been submitted to ICDD® for inclusion in the Powder Diffraction File ${ }^{\mathrm{TM}}$ (PDF®). ( $) 2020$ International Centre for Diffraction Data.
\end{abstract}

[doi:10.1017/S0885715619000927]

Key words: trimethoprim, Primsol, powder diffraction, density functional theory

Trimethoprim (Primsol) is an antibiotic used primarily to treat bladder infections. Other uses include treating middle ear infections and traveler's diarrhea. Commercial trimethoprim, CAS \#738-70-5, crystallizes in the triclinic space group $P-1$ (\#2) with $a=10.5085(3), b=11.2000(2), c=8.05869(13) \AA$, $\alpha=101.2337(2), \quad \beta=112.1787(3), \quad \gamma=112.6321(4)^{\circ}, \quad V=$ $743.729(3) \AA^{3}$, and $Z=2$. A reduced cell search in the Cambridge Structural Database (Groom et al., 2016) yielded three previous structure determinations, using X-ray data collected at $100 \mathrm{~K}$ (Maddileti et al., 2015), $173 \mathrm{~K}$ (Rauf and Bolte, 2006), and neutron data assumed to be collected at room temperature (Koetzle and Williams, 1976; Figure 1).

In this work, the sample was ordered from the United States Pharmacopeial Convention (USP) (Lot \#L0M053) and analyzed as-received. The diffraction data for this study were collected on beamline 11-BM at the Advanced Photon Source, Argonne National Laboratory. The room temperature $(295 \mathrm{~K})$ crystal structure was refined using synchrotron $(\lambda=$ $0.412826 \AA$ ) powder diffraction data and optimized using density functional theory techniques. Hydrogen positions were included as a part of the structure and were re-calculated during the refinement.

We found hydrogen bonding patterns consistent with the previous determinations. In addition, we identified two $\mathrm{C}-\mathrm{H} \cdots \mathrm{O}$ hydrogen bonds, which also contribute to the crystal

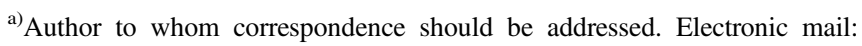
kaduk@polycrystallography.com
}

energy. When comparing the previously reported trimethoprim structure determinations, the lattice parameters were found to contract at lower temperatures, particularly $100 \mathrm{~K}$ (Figure 2). All structures show reasonable agreement, with unit cell differences ranging between 0.05 and $0.15 \AA$. These differences will have an effect on diffraction peak positions and subsequently phase identification at room temperature, thus the need for high-quality, room temperature X-ray diffraction data (Kaduk et al., 2014). The powder X-ray diffraction pattern of the compound has been submitted to ICDD ${ }^{\circledR}$ for inclusion in the Powder Diffraction File ${ }^{\mathrm{TM}}$ (PDF®) (Gates and Blanton, 2019; Table I).

\section{DEPOSITED DATA}

CIF and/or RAW data files were deposited with ICDD. You may request this data from ICDD at info@icdd.com.

\section{ACKNOWLEDGEMENTS}

The authors thank the Student Inquiry and Research Program from the Illinois Mathematics and Science Academy for providing this research opportunity.

\section{FUNDING INFORMATION}

The use of the Advanced Photon Source at the Argonne National Laboratory was supported by the U.S. Department of Energy, Office of Science, and Office of Basic Energy 
TABLE I. Hydrogen bonds (CRYSTAL14) in trimethoprim.

\begin{tabular}{|c|c|c|c|c|c|c|}
\hline H-bond & D-H (A) & $\mathrm{H} \cdots \mathrm{A}(\AA)$ & $\mathrm{D} \cdots \mathrm{A}(\AA)$ & $\mathrm{D}-\mathrm{H} \cdots \mathrm{A}\left({ }^{\circ}\right)$ & Overlap (e) & $E\left(\mathrm{kcal} \mathrm{mol}^{-1}\right)$ \\
\hline $\mathrm{N} 2-\mathrm{H} 1 \cdots \mathrm{N} 1$ & 1.025 & 1.988 & 3.011 & 175.3 & 0.067 & a \\
\hline $\mathrm{N} 2-\mathrm{H} 5 \cdots \mathrm{O} 2$ & 1.011 & 2.097 & 2.923 & 137.4 & 0.029 & 3.9 \\
\hline $\mathrm{N} 4-\mathrm{H} 7 \cdots \mathrm{N} 3$ & 1.026 & 1.988 & 3.012 & 175.8 & 0.070 & a \\
\hline 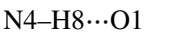 & 1.010 & 2.448 & 3.251 & 136.0 & 0.018 & 3.1 \\
\hline C10-H9...O3 & 1.090 & 2.516 & 3.587 & 167.2 & 0.018 & a \\
\hline C11-H10 … 8 & 1.082 & $2.695^{\mathrm{b}}$ & 3.043 & 98.1 & 0.013 & a \\
\hline
\end{tabular}

${ }^{\mathrm{a}}$ Correlation between overlap population and hydrogen bond energy not yet available for $\mathrm{C}-\mathrm{H} \cdots \mathrm{O}$ and $\mathrm{N}-\mathrm{H} \cdots \mathrm{N}$ hydrogen bonds.

${ }^{\mathrm{b}}$ Intramolecular.

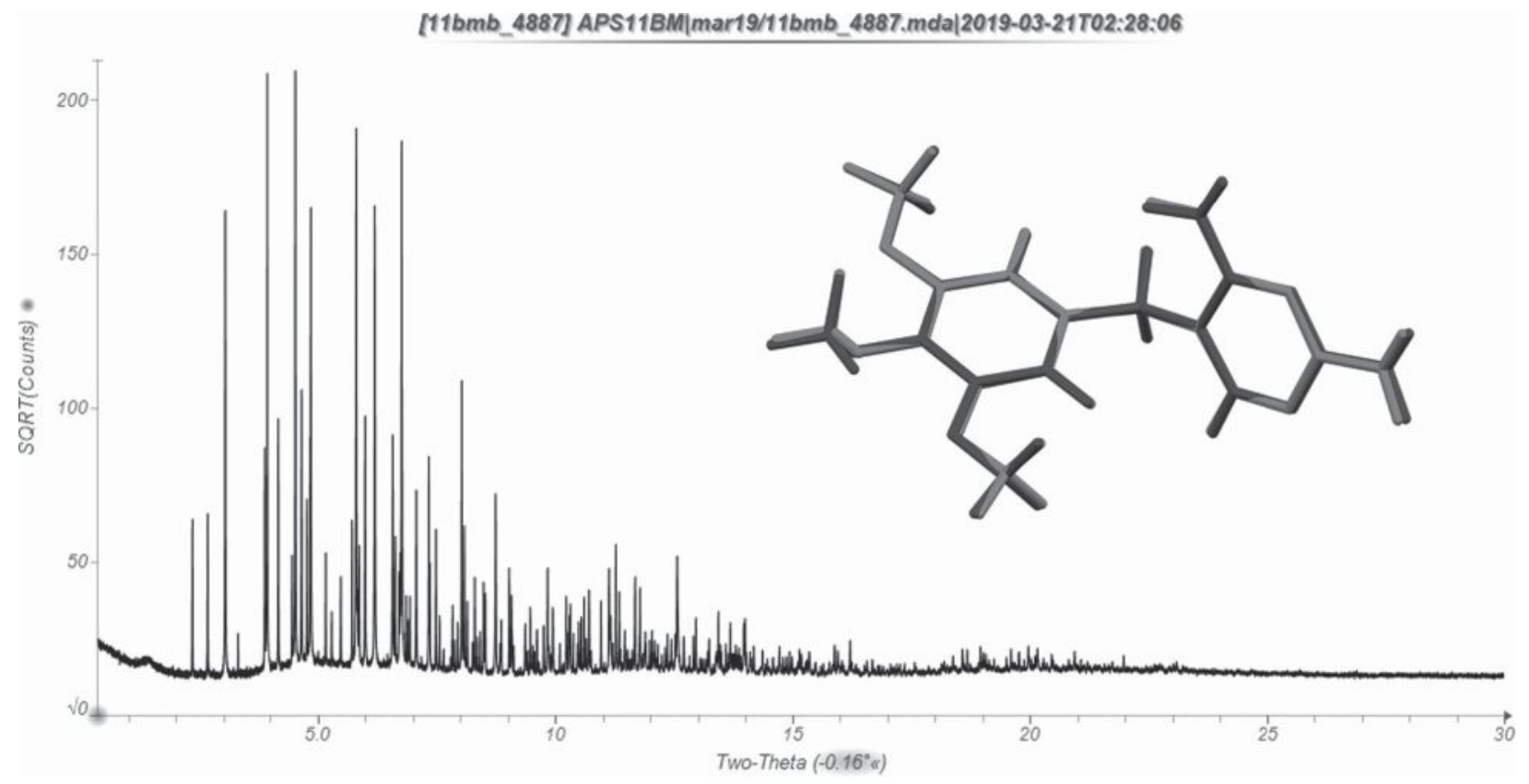

Figure 1. (Colour online) Powder X-ray diffraction pattern of trimethoprim. The Rietveld-refined structure is indicated in red, and the density functional theoryoptimized structure is indicated in blue.

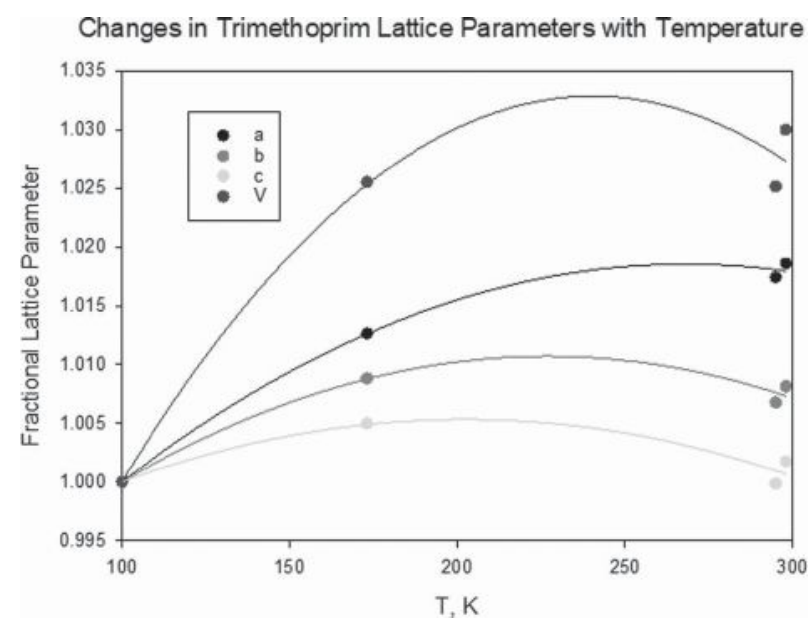

Figure 2. (Colour online) Lattice parameters of trimethoprim as a function of the temperature. The curves are intended to guide the eye.
Sciences under Contract No. DE-AC02-06CH11357. This work was partially supported by the International Centre for Diffraction Data (ICDD).

Gates-Rector, S. and Blanton, T. (2019). "The Powder Diffraction File: a quality materials characterization database," Powder Diffr. 34(4), 352-360.

Groom, C. R., Bruno, I. J., Lightfoot, M. P., and Ward, S. C. (2016). "The Cambridge Structural Database,” Acta Crystallogr. B. 72, 171-179.

Kaduk, J. A., Crowder, C. E., Zhong, K., Fawcett, T. G., and Suchomel, M. R. (2014). "Crystal structure of atomoxetine hydrochloride (Strattera), $\mathrm{C}_{17} \mathrm{H}_{22} \mathrm{NOCl}$," Powder Diffr. 29(3), 269-273.

Koetzle, T. F. and Williams, G. J. B. (1976). "The crystal and molecular structure of the antifolate drug trimethoprim (2,4-diamino-5-(3,4,5-trimethoxybenzyl)pyrimidine)," J. Am. Chem. Soc. 98, 2074-2078.

Maddileti, D., Swapna, B., and Nangia, A. (2015). "Tetramorphs of the antibiotic drug trimethoprim: characterization and stability," Cryst. Growth Des. 15, 1745-1746.

Rauf, K. and Bolte, M. (2006). CSD Communication; Refcode AMXBPM11. 